\title{
Correction to: Toxicity and repellent effects of wood extractives of five Malaysian wood species on Asian subterranean termite Coptotermes gestroi Wasmann
}

\author{
Roszaini Kadir $^{1}\left[\right.$ B Babar Hassan ${ }^{2}$
}

Published online: 28 September 2020

๑) Springer-Verlag GmbH Germany, part of Springer Nature 2020

\section{Correction to: European Journal of Wood and Wood Products \\ https://doi.org/10.1007/s00107-020-01592-z}

In the original publication, the second author name was incorrectly published as Hassan Babar.

The correct name should read as "Babar Hassan".

The original article can be found online at https://doi.org/10.1007/ s00107-020-01592-z.

Roszaini Kadir

roszaini@frim.gov.my

1 Forest Product Division, Forest Research Institute of Malaysia (FRIM), 52109 Kepong, Selangor Darul Ehsan, Malaysia

2 Department of Entomology, South China Agricultural University, Guangzhou 510642, China 